\title{
ELECTROMYOGRAPHIC AND ENDOCRINE STUDIES IN CHRONIC THYROTOXIC MYOPATHY
}

\author{
BY \\ K. V. SANDERSON and W. R. ADEY \\ From the Royal Adelaide Hospital and the Department of Anatomy, the University of Adelaide
}

If the number of cases of a disease reported in the literature can be taken as an index of frequency, chronic thyrotoxic myopathy is a very rare disease. Its interest lies, however, not so much in its rarity as in the light it may throw on the inter-relationship of the endocrine glands and muscle function.

In a previous paper (Sanderson and Adey, 1949) some aspects of this problem were reviewed and a case was reported in which the electromyographic findings were those typical of muscle dystrophy. Two further cases are presented here with the electromyographic findings, and with investigation of the function of the adrenal cortex in one case.

The electromyograms give positive evidence of a muscular dystrophy of severe degree and show a return to the normal pattern after treatment of the thyrotoxicosis, thus making the diagnosis beyond doubt. The tests of adrenal cortical function were designed in rather a hurry and partly for this reason, but more especially because such tests are comparatively crude, the evidence for depressed function is inconclusive. That such a depression of function may occur in this disease is suggested by the necropsy findings of Thorn and Eder (1946) of atrophy of the glomerular layer of the adrenal cortex.

\section{Case Reports}

Case 1.-Mrs. M. C., aged 55, was admitted to the Royal Adelaide Hospital on July 8, 1949. At the age of 11 months she had suffered from infantile paralysis which had left the right arm and right leg weakened. However, she had always been active and done her own housework, and was married and had three children. Six months before admission she began to have shaking of the limbs and palpitation, and she became unduly excitable; she also noticed weakness of the limbs. The weakness progressed until at the time of admission she could not walk without support. She had lost 28 lb. in weight in the previous six months. The menopause occurred five years before.

Examination showed her to be very thin, weighing $74 \frac{1}{2} \mathrm{lb}$., with slightly staring eyes and a visible swelling of the neck. The thyroid gland was evenly enlarged, soft and smooth. The pulse rate was 90 , the blood pressure $150 / 60 \mathrm{~mm}$. of mercury. No abnormality was found on examination of the cardiovascular system, respiratory system, or the abdomen. There was considerable wasting and gross weakness of the muscles of the limbs. The muscles of the right upper arm, the flexors of the fingers on the right side, and the extensors of the right knee were much more severely affected than the rest of the limb muscles. Fasciculation was noted in the right quadriceps femoris muscle. The tendon reflexes were all present in the left arm, but those of the biceps and triceps brachii were absent in the right arm. The only reflex obtained in the legs was the right ankle jerk. The plantar responses were flexor. There was a fine tremor of the fingers. The urine was normal.

She was given an injection of $0.5 \mathrm{mg}$. of " prostigmin " on two occasions. She claimed that there was a definite increase in power after the first, but two days later there was no response. Her basal metabolic rate was $+28 \%$. An electromyogram from the left deltoid muscle was diagnostic of a myopathy and did not suggest the presence of a long-standing lower motor neuron lesion such as poliomyelitis.

After preparation with iodine, subtotal thyroidectomy was performed by Mr. Ian Hamilton. Histological examination of the gland showed hyperplasia and the formation of some papillary processes. Her convalescence was satisfactory and she was discharged showing some improvement in muscular power. A further electromyogram eight weeks after the first indicated that the myopathic process was still present but there was some evidence of recovery.

Her case was reviewed in August, 1951. She was then able to do her housework, and said that her muscular power and weight had returned to what they had been before her illness began. She was no longer excitable and was sleeping well. Examination showed no exophthalmos and no tremor, the pulse rate was 72 , and there was a considerable increase in muscle bulk, even in those muscles previously affected by poliomyelitis. The muscular power was very much increased. Her weight was $100 \mathrm{lb}$. An electromyogram was not' performed at this time.

Case 2.-E.B., a pensioner, 68 years old, was admitted to the Royal Adelaide Hospital on May 16, 1951. He complained of progressive weakness, muscular cramps, 
loss of weight, and vomiting for six months. The loss of weight began 18 months before and at the time of admission amounted to $70 \mathrm{lb}$. Six months previously he began to notice difficulty in climbing stairs and in getting out of chairs, and about the same time he found that if he had to stand for any length of time he would vomit. The vomiting was preceded by nausea and related only to standing. He was not irritable and did not sweat excessively. He had disliked hot weather all his life and became very shaky at times. His appetite had always been good. At the time of admission he was very weak, but did not complain of fatiguability. He was suffering from muscular cramps at night. His relatives had noticed that his voice had altered. His previous illnesses were jaundice and trench fever in the 1914-18 war. He could give no details of family illnesses.

On examination he was a very thin and weakened elderly man with a mild degree of exophthalmos. The thyroid gland was smoothly and uniformly enlarged. The pulse rate was 96 , the blood pressure $155 / 65 \mathrm{~mm}$. of mercury. The cardiovascular and respiratory systems and the abdomen were normal. Rectal examination showed the prostate gland somewhat enlarged but normal in other respects. The testes were normal. Palmar erythema was present and there was a fine tremor of the fingers. The tongue was long and thin, and no fasciculation was noted ; the palate moved less than normal. His voice was gruff and had the windy quality that goes with palatal weakness. The vocal cords moved normally. There was a generalized gross muscle wasting affecting the roots of the limbs somewhat more than the extremities, and this was accompanied by very considerable weakness, especially of the triceps brachii and quadriceps femoris muscles. Occasional fascicular twitching was seen in the triceps, quadriceps, and interossei muscles of the hands. Tendon jerks were all present, equal, but less active than normal. The plantar responses were flexor and the abdominal reflexes were present. The urine was normal. His weight was $104 \mathrm{lb}$. His sleeping pulse rate varied from 84 to 96 .

Special Investigations.-The only abnormality found by haematological examination was a mild degree of anaemia (haemoglobin $11 \cdot 3 \mathrm{~g} . \%$ ). The blood urea was $28 \mathrm{mg} . \%$, the serum electrolyte levels were sodium $140 \mathrm{~m} . \mathrm{Eq} /$ litre (method of Noyons), potassium $5 \cdot 1$ m.Eq/litre (method of Abul Fadl), and chloride 108 m.Eq/litre. The B.M.R. was $+30 \%$. No abnormality was found on radiological examination of the chest or by an opaque meal, but examination of the spine, pelvis, and femora revealed severe osteoporosis. An electrocardiogram showed the $\mathrm{S}-\mathrm{T}$ segment down-sloping in leads 2, 3 and V6, and the T waves low or diphasic in these leads suggesting myocardial disorder or damage. A tracing after two weeks' treatment was normal. Tests of liver function were normal. A glucose tolerance test gave the following levels : fasting $0.09 \mathrm{~g} . \%$, half an hour after $50 \mathrm{~g}$. glucose $0.16 \mathrm{~g} . \%$, one hour $0.11 \mathrm{~g} . \%$, one and a half hours $0.08 \mathrm{~g} . \%$, two hours $0.07 \mathrm{~g} . \%$ (Folin Wu method on venous blood). The Robinson-
Power-Kepler test was positive on two occasions, the values for " $A$ " being 4.9 and 8 . The fall in eosinophils four hours after the injection of $0.3 \mathrm{mg}$. of adrenalin was $35 \%$ and after $25 \mathrm{mg}$. A.C.T.H. was $54 \%$. The urinary excretion of 17 -ketosteroids was $12.4 \mathrm{mg}$. in 24 hours, of creatine $0.008 \mathrm{~g}$., and creatinine $0.68 \mathrm{~g}$. The electromyographic findings are discussed below.

Treatment and Course.-Treatment with methyl thiouracil was begun on May 27, the dose being $200 \mathrm{mg}$. daily for four weeks, $100 \mathrm{mg}$. for a further four weeks, and $50 \mathrm{mg}$. daily thereafter. He was given a diet containing at least $200 \mathrm{~g}$. of protein a day supplemented with vitamins of the B group parenterally. He improved steadily, gaining $10 \mathrm{lb}$. weight in the first four weeks. The sleeping pulse rate fell to below 80 . The bulk and power of the muscles gradually increased, the palate regained full movement, and the exophthalmos disappeared. The patient was most gratified with his improvement, but complained of pains in the joints of the upper limbs. Three weeks after treatment was begun he developed peri-articular swelling and limited mobility of the finger joints. After eight weeks' treatment the B.M.R. had fallen to $-4 \%$ and the Robinson-PowerKepler test gave a negative result. The patient continued to improve steadily, gaining in weight and strength, and was able to resume his normal activity. The symptoms of arthritis in the fingers and shoulders lessened during the fourth month of treatment, and when last reviewed on September 18 he had no peri-articular swelling, a full range of movements, and muscular power and development normal for a man of his age. He had not vomited and his weight was $160 \mathrm{lb}$.

\section{Tests of Adrenal Function in Case 2}

The serum electrolyte levels were all normal. The Robinson-Power-Kepler test, which was abnormal on two occasions before treatment was begun indicating impaired adrenal function, returned to normal after the thyrotoxicosis was controlled. The glucose tolerance curve was within normal limits. The urinary excretion of 17-ketosteroids was normal. The eosinophil response to adrenalin was $35 \%$ depression compared with the normal $50 \%$ or more (Recant, Hume, Forsham, and Thorn, 1950). The eosinophil response to A.C.T.H. was $54 \%$ depression, a normal result. Taken together these two responses suggest subnormal production of A.C.T.H. by the anterior pituitary causing adrenal insufficiency (Recant, Forsham, and Thorn, 1948).

During the first five weeks of treatment eosinophil counts were done by the method of Dunger on capillary blood, four days a week at 10 a.m. and 2 p.m. Every second day a subcutaneous injection of $0.3 \mathrm{mg}$. of adrenalin was given after the first specimen was taken, the other days being used as controls. During this period there was a conspicuous clinical improvement and it was hoped 
TABLE I

PERCENTAGE ALTERATION IN CIRCULATING EOSINOPHILS

\begin{tabular}{|c|c|c|c|c|c|c|c|c|c|c|c|c|c|c|c|c|}
\hline \multirow{2}{*}{\multicolumn{3}{|c|}{ After $0.3 \mathrm{mg}$. adrenalin }} & & \multirow[b]{2}{*}{. } & \multirow[b]{2}{*}{. } & \multicolumn{2}{|c|}{ 1st Week } & \multicolumn{2}{|c|}{ 2nd Week } & \multicolumn{2}{|c|}{ 3rd Week } & \multicolumn{2}{|c|}{ 4th Week } & \multicolumn{2}{|c|}{ 5th Week } & \multirow{2}{*}{$\frac{\text { Mean }}{-30 \pm 2.42}$} \\
\hline & & & & & & -32 & -36 & -24 & -26 & -15 & -31 & -31 & -33 & -43 & -29 & \\
\hline Control & .. & . & . & . & .. & -18 & -10 & -26 & +3 & +15 & +12 & -8 & -10 & -4 & +14 & $-3 \cdot 2 \pm 4 \cdot 07$ \\
\hline
\end{tabular}

that the eosinophil response would show a corresponding temporal regression, indicating an improved adrenal function. The results are summarized in Table I.

The figures obtained were analysed statistically. No significant temporal regression could be demonstrated in this series, or in the absolute eosinophil counts from which it is derived. The mean of the control series did not differ significantly from 0 . The mean of the adrenalin series was $30 \pm 2.42 \%$ depression.

Periodic further adrenalin eosinophil responses remained subnormal, the last giving $44 \%$ depression on September 18.

\section{Electromyographic Findings in Case 2}

The electromyographic studies were carried out by inserting a concentric needle electrode into the right triceps muscle, which was fairly representative in its degree of wasting. The needle electrode was prepared by running an insulated wire through the shaft of a hypodermic needle. The end of this wire is bared and projects through the bevelled orifice of the needle. The sheath of the needle acts as a shield to the bared wire tip, which thus records the electrical activity only from motor units in the immediate vicinity of the needle tip (approximately for a distance of $0.5 \mathrm{~cm}$.). Activity in individual motor units is thus easily recorded by means of a five-stage amplifier and twin-beam cathode-ray oscilloscope.

At the first examination on May 22, 1951, six days after admission to hospital, the number of motor units active during voluntary contraction of the right triceps muscle was considerably reduced, and the voltage from these units below normal. Fibrillation potentials, which would indicate some neurogenic lesion, were not seen when the muscle was at rest.

An analysis, after the method of Petersén and Kugelberg (1949), was made of the activity in 82 different motor units during voluntary contraction. The duration of these units is very greatly reduced from the normal 5-10 m.sec., with a preponderance in the range 2-4 m.sec. (Figs. 1 and 2). Statistical analysis shows a mean duration of $3.8 \mathrm{~m} . \mathrm{sec}$. A histogram from the normal biceps is presented for comparison. No action potentials with a duration longer than $11 \mathrm{~m} . \mathrm{sec}$. were seen, and all those longer than $6 \mathrm{~m} . \mathrm{sec}$. were highly polyphasic. These changes are diagnostic of a muscular dystrophy.

A further test on June 26, 1951, showed that there was still an undue proportion of action potentials in the range 4-6 m.sec. An appreciable number of spikes in the range 10-14 m.sec. had reappeared, but they were polyphasic in most cases. As in the previous test, no fibrillation potentials were seen at rest. The histogram of 82 different action potentials on this occasion shows an appreciable reversion to the normal type. The mean duration was 5.7 m.sec.

A third electromyograph on August 8, 1951, showed still further improvement, with considerably more action potentials in the range 10-17 m.sec. than at the time of the second test. However, persistent fast activity was still present in an appreciable number of motor units in the range 1-3 m.sec. The presence of numerous highly polyphasic units in this test made the interpretation difficult. The histogram was prepared from only 48 units. The mean was $6.2 \mathrm{~m} . \mathrm{sec}$.

A final examination on September 19, 1951, produced a histogram of 61 different motor units which is essentially that of a normal muscle. No action potentials with a duration of less than $3 \mathrm{~m} . \mathrm{sec}$. were seen, and the mean duration was $7 \cdot 3 \mathrm{~m}$.sec.

The electromyographic findings illustrated by the histograms were subjected to detailed statistical analysis and compared with the values given by Petersén and Kugelberg for the normal biceps muscle. These authors presented their results as a histogram, and from this the frequency distribution of action potential duration was reconstructed. It is possible that a little inaccuracy resulted here. However, the close correspondence of the mean and variance of the mean calculated from these figures with the values given by Petersén and Kugelberg show that any errors introduced by this procedure have been slight.

Table II gives the statistics of the distributions of the action potential duration (in milliseconds) of the four tracings we made in Case 2 and those computed from Petersén and Kugelberg. 
CASE 2. (E.B.).
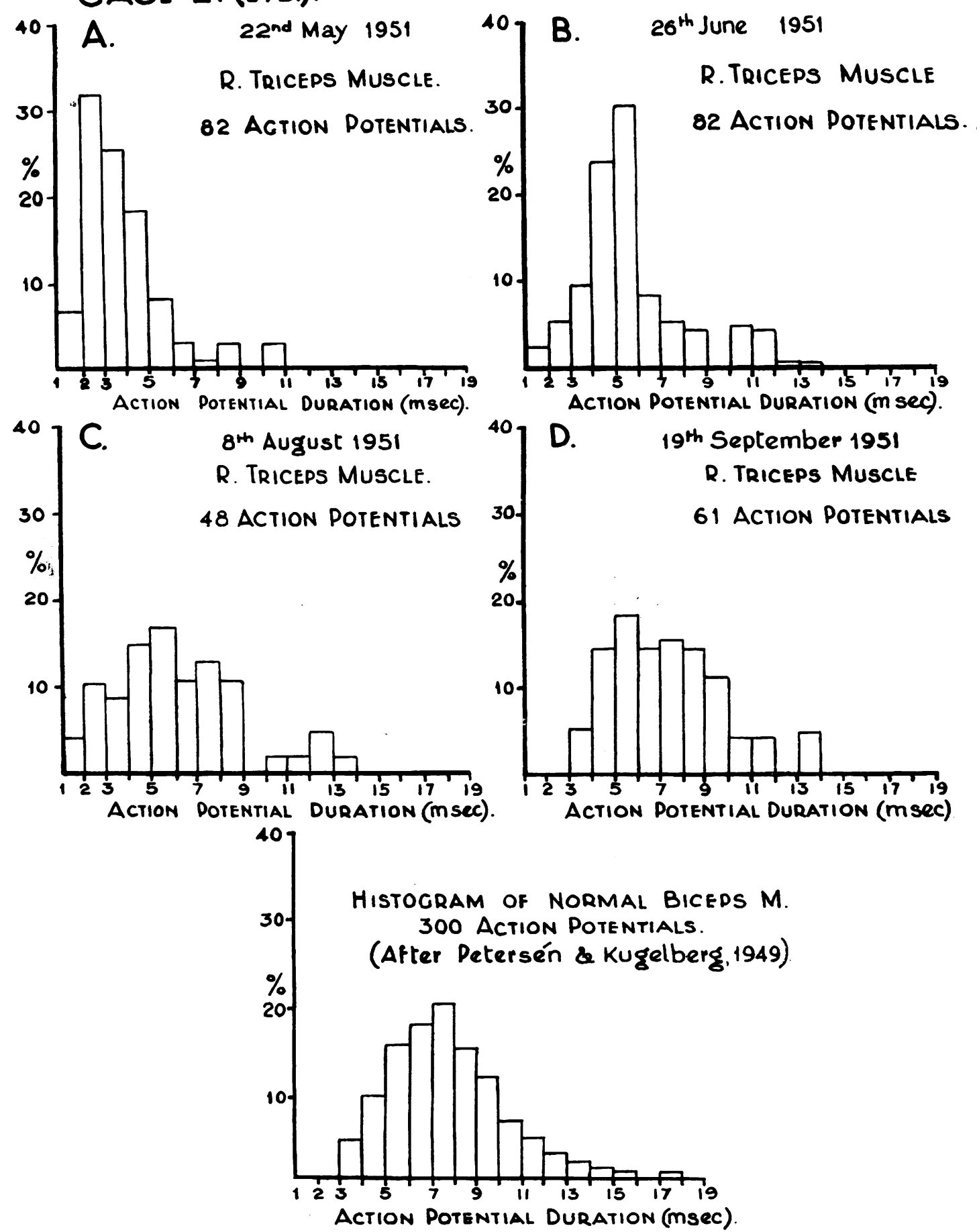

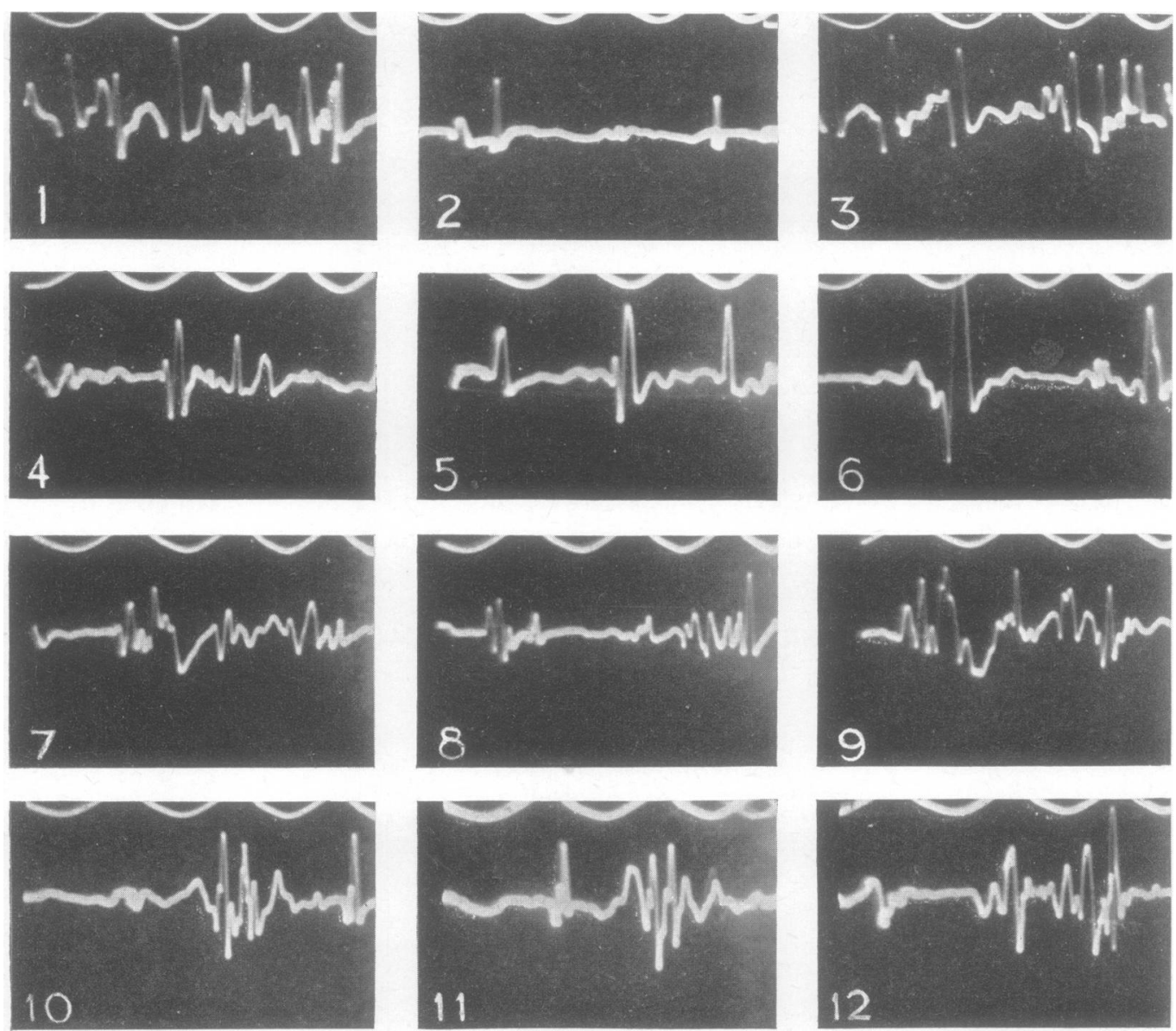

Fig. 2.-All tracings from the right triceps muscle. Time markers $=20 \mathrm{~m} . \mathrm{sec}$.

Tracings 1, 2, and 3 from the first electromyograph on May 22, 1951, showing numerous action potentials in the range 2-4 m.sec. Tracings 4,5 , and 6 from the second electromyograph on June 26,1951 . The number of short duration potentials was less than at the first test.

Tracings 7, 8, and 9 from the third electromyograph on August 8, 1951. The mean duration at this test was $6 \cdot 2 \mathrm{~m} . \mathrm{sec}$.

Tracings 10,11, and 12 from the fourth electromyograph on September 19, 1951. Mean duration $7 \cdot 3$ m.sec.

The mean action potential duration shows a progressive increase from trace I to trace IV. When the difference between the various tracings is tested it is found to be highly significant between I and II, not significant between II and III, significant between III and IV, and not significant between IV and the normal. The value of trace III is lessened because of the smaller rumber of observations for comparison. The results of the tests of significance are shown in Table III.

This statistical analysis, therefore, confirms the impression gained from inspection of the histograms that the electromyogram taken before treatment was grossly abnormal, and that those taken during the course of treatment progressively improved, the last tracing being almost normal.

\section{Discussion}

Our knowledge of chronic thyrotoxic myopathy has been adequately reviewed in the papers of Brain and Turnbull (1938), McEachern and Ross (1942), Thorn and Eder (1946), Devic, Froment, Guinet, and Devic (1947) and Sanderson and Adey (1949). It has been postulated that the thyrotoxic muscular disorders result from the action of several endocrine factors on striated muscle and that the type of disorder produced depends on the pattern of endocrine disturbance. However, the nature of 
TABLE II

DISTRIBUTION OF ACTION POTENTIAL DURATION

\begin{tabular}{|c|c|c|c|c|c|c|}
\hline & & Trace I & Trace II & Trace III & [Trace IV & Normal \\
\hline No. of obs & servations & 82 & 82 & 48 & 61 & 300 \\
\hline Mean & . & $3 \cdot 80$ & $5 \cdot 73$ & $6 \cdot 21$ & $7 \cdot 27$ & $7 \cdot 59$ \\
\hline Variance & .. & $3 \cdot 3010$ & $6 \cdot 1061$ & 8.9770 & 6.0802 & 5.9578 \\
\hline $\begin{array}{c}\text { Variance } \\
\text { mean }\end{array}$ & $\begin{array}{l}\text { of the } \\
\cdots\end{array}$ & 0.0403 & 0.0745 & $0 \cdot 1870$ & $0 \cdot 1013$ & 0.0199 \\
\hline $\mathbf{g}_{1} \quad \ldots$ & $\cdots$ & 1.6966 & $1 \cdot 2011$ & 0.7052 & 0.7413 & 0.9009 \\
\hline $\mathbf{g}_{2}$ & . & $3 \cdot 7043$ & 1.4413 & $0 \cdot 1018$ & $0 \cdot 2623$ & 1.4489 \\
\hline
\end{tabular}

TABLE III

RESULTS OF TESTS OF SIGNIFICANCE

\begin{tabular}{|c|c|c|c|}
\hline $\begin{array}{l}\text { Testing Difference } \\
\text { between Means }\end{array}$ & & S.N.D.* & $\mathbf{P} \dagger$ \\
\hline Trace I and II & .. & $5 \cdot 687$ & $<\cdot 001$ \\
\hline Trace II and III & . & 0.932 & .35 \\
\hline Trace III and IV & .. & 1.971 & $<\cdot 05$ \\
\hline Trace II and normal.. & . & $6 \cdot 060$ & $<.001$ \\
\hline Trace III and normal & . & 3.045 & $<\cdot 01$ \\
\hline Trace IV and normal & . & 0.938 & $\cdot 35$ \\
\hline
\end{tabular}

* Standard normal deviation. †The probability that the difference is due to the action of chance.

the interaction of the thyroid with other endocrine glands is still imperfectly understood, and the reason why on very rare occasions a patient with thyrotoxicosis develops severe myopathy or myasthenia gravis is completely obscure. The importance of chronic thyrotoxic myopathy, from the viewpoint of experimental medicine therefore, is that there is an inter-related disturbance of thyroid and muscle function, probably mediated by the anterior pituitary-adrenal system which can be varied at will by the use of antithyroid drugs. It seems likely that a close study of these patients would add to our knowledge of this still obscure branch of endocrinology.

The present electromyographic observations confirm and amplify those we previously reported. After the patient is treated the return to the normal pattern appears to take two or three months. The comparison of serial tracings is made more precise by the analysis of action potential duration.

Our findings support the suspicion that adrenal function is depressed in this disease. In our experience the eosinophil response têst is not so sensitive or accurate a measure of adrenal function as some reports have suggested, and the RobinsonPower-Kepler test is the most sensitive test available. In the related condition of myasthenia gravis and malignant exophthalmos Zondek and Ticho (1951) have reported a positive Robinson-Power-Kepler test which became normal after treatment.

\section{Summary}

Two further cases of chronic thyrotoxic myopathy are reported. The electromyographic findings in one case are illustrated and described. These were diagnostic of myopathy and returned to the normal pattern after control of the thyrotoxicosis. Statistical analysis of the duration of the motor unit action potentials has been used to assess the change.

Tests of the function of the adrenal cortex on one patient gave inconclusive results. Serial estimations of the eosinophil depression in response to adrenalin showed no change during the first five weeks of treatment with thiouracil. The RobinsonPower-Kepler test, positive before treatment, became normal after the thyrotoxicosis was controlled. The eosinophil response was still subnormal after four months' treatment although the patient appeared to have recovered completely.

The authors are indebted to the Board of Management of the Royal Adelaide Hospital and to Drs. Guy Lendon and J. G. Sleeman for permission to report the two cases, and to Professor A. A. Abbie, Department of Anatomy, University of Adelaide, for the facilities to perform the electromyograms. Dr. E. A. Cornish of the Commonwealth Scientific and Industrial Research Organisation gave much assistance by carrying out the statistical analyses. The special investigations were performed by members of the staff of the Institute of Medical and Veterinary Science, Adelaide.

\section{REFERENCES}

Brain, W. R., and Turnbull, H. M. (1938). Quart. J. Med., n.s., 7, 293.

Devic, A., Froment, R., Guinet, P., and Devic, M. (1947). J. Méd. Lyon, 28, 155.

McEachern, D., and Ross, W. D. (1942). Brain, 65, 181.

Petersén, I., and Kugelberg, E. (1949). Journal of Neurology, Neurosurgery and Psychiatry, 12, 124.

Recant, L., Forsham, P. H., and Thorn, G. W. (1948). J. clin. Endocr., 8, 589.

L, Hume, D. M., Forsham, P. H., and Thorn, G. W. (1950). Ibid., 10, 187.

Sanderson, K. V., and Adey, W. R. (1949). Med. J. Aust., 1, 797.

Thorn, G. W., and Eder, H. A. (1946). Amer. J. Med., 1, 583.

Zondek, H., and Ticho, A. (1951). Lancet, 2, 1018. 